\title{
Preparation and characterization of a novel bone graft composite containing bone ash and egg shell powder
}

\author{
GUNASEKARAN KRITHIGA and THOTAPALLI P SASTRY* \\ Central Leather Research Institute, Chennai 600 020, India
}

MS received 28 July 2009; revised 14 September 2009

\begin{abstract}
Egg shells which were hitherto discarded as wastes were collected, purified and powdered into a particle size in the range of 5-50 $\mu \mathrm{m}$. A composite bone graft material in cylindrical form was prepared using egg shell powder (ESP), bone ash (BA) and gelatin. These bone grafts were characterized for their FT-IR, TGA, XRD, SEM and mechanical properties. The mechanical studies indicate that the composite having a stoichiometric ratio of BA (3 g) and ESP ( $7 \mathrm{~g}$ ) has shown better mechanical properties. X-ray diffraction (XRD) data indicated the crystallographic nature of BA is akin to hydroxyapatite (HA) and both BA and ESP did not lose their crystalline nature when bone grafts were prepared. This revealed that ESP may be used as a component in bone graft utilizing the solid waste from the poultry industry.
\end{abstract}

Keywords. Egg shell powder; bone ash; bone graft; gelatin; poultry industry; solid waste.

\section{Introduction}

Calcium and phosphorus are essential nutrients for all vertebrates and it is also well known that human bone contains $\sim 70 \%$ inorganic (apatite calcium phosphate) and 30\% organic (mostly collagen) materials by weight. Hydroxyapatite, which resembles the inorganic part of bone, has received great attention in the world of biomaterials. Synthetic hydroxyapatite is prepared using a variety of chemical synthesis routes and reagents. Some of the techniques include wet processing (Monma and Kamiya 1987), dry processing (Fowler 1974), synthesizing via biological tissues (Liji Sobhana et al 2009; Sundaraseelan and Sastry 2007), sol-gel techniques (Yoshio et al 1990), electrochemical deposition etc. In our earlier studies, we have prepared calcined bone-based bone graft, and characterized and evaluated the same for its bone inducing capacity. We found that calcined bone exhibited similar crystallographic characteristics of hydroxyapatite (Noorjahan and Sastry 2005). In this study, we have used egg shell powder along with bone ash powder to prepare the implant and studied some of the physicochemical characteristics of the implant.

Egg shell which constitutes about $11 \%$ of the total weight of the whole egg contains about $91 \%$ of $\mathrm{CaCO}_{3}$ (Rivera et al 1990; Nakano et al 2003). It is reported that 1,90,000 tonnes of egg shell is wasted in India and might be used as a calcium source in human nutrition (Schaafsma et al 2000). The biological behaviour of this natural material has

\footnotetext{
*Author for correspondence (sastrytp@ hotmail.com)
}

also shown that it could be used as a bone substitute in the field of maxillofacial surgery (Dupoirieux et al 1995, 2000, 2001; Dupoirieux 1999). Egg shell particles ranging from 400-600 $\mu \mathrm{m}$ were bioassayed in the intramuscular pouches of rodents and their osteoinductive nature studied. It was reported that the particles did not exhibit osteoinductive capacities. After a 6-month study the authors have concluded that the egg shell powder could be used as a filler material in the bone defects of non-weight bearing areas. Sasikumar et al reported a simple combustion technique for synthesizing nanocrystalline hydroxyapatite powder from eggshell, diammonium hydrogen phosphate and citric acid. Using this method, the authors were able to control the particle size distribution and morphology of hydroxyapatite (Sasikumar and Vijayaraghavan 2006). Hydroxyapatite was also synthesized by several authors using egg shell as the starting material (Dasgupta et al 2004; Prabakaran et al 2005).

Hydroxyapatite is well known for its osteoconductive properties and widely used by clinicians worldwide (Shiny et al 2000; Gregory Lee et al 2005; Best et al 2008). In the present study, we have prepared bone grafts in cylindrical form using egg shell powder (ESP) and calcite bone powder along with gelatin, and partial characterization of these materials was carried out.

\section{Experimental}

\subsection{Methods}

2.1a Preparation of bone ash: Tibial bones of the cattle were collected from a nearby slaughter house. The bones 
were cut into $2 \times 2^{\prime \prime}$ pieces using a prebeaker. Then the bone pieces were incinerated at $300^{\circ} \mathrm{C}$ and ashed at $750^{\circ} \mathrm{C}$ for about $5 \mathrm{~h}$. This treatment made organic matter present in the bone to get volatilized and resulted in the formation of bone ash, which was nothing but the inorganic part of the bone which was denoted as bone ash (BA).

2.1b Preparation of gelatin: Gelatin powder from bovine source having 250 Bloom strength was kindly supplied by Maruthi Gel Company Ltd, Trichy, India. Five g of gelatin powder was dissolved in $12 \mathrm{ml}$ of water at $50^{\circ} \mathrm{C}$ with constant stirring. This solution was denoted as ' $G$ '.

2.1c Preparation of egg shell powder (ESP): Egg shells were collected from a nearby restaurant and washed thoroughly, initially in tap water and later in distilled water. The adhering membrane was separated manually and shells were dried at room temperature $\left(30^{\circ} \mathrm{C}\right)$. Later the shells were crushed using a domestic mixer, to a particle size in the range of 5-50 $\mu \mathrm{m}$. The powdered ESP was stored in polythene covers at room temperature $\left(30^{\circ} \mathrm{C}\right)$ till further use.

2.1d Preparation of ESP with $G(E S P-G)$ : To $6 \mathrm{ml}$ of gelatin solution, $10 \mathrm{~g}$ of ESP was added, contents were mixed well and made into paste using a mortar and pestle. With the help of glass tube with a diameter of $1.2 \mathrm{~cm}$ the paste was extruded as cylindrical implant. After $2 \mathrm{~h}$ of air drying the implants were cured at $80^{\circ} \mathrm{C}$ for $12 \mathrm{~h}$.

2.1e Preparation of $B A$ with $G(B A-G)$ : To $6 \mathrm{ml}$ of gelatin solution $10 \mathrm{~g}$ of BA was added, contents were mixed well and made into paste using a mortar and pestle. The implant preparation was followed as explained in the case of ESP-G.

2.1f Preparation of ESP-BA with $G(E S P-B A-G)$ : To a mixture containing different amounts of ESP and BA (table 1), $6 \mathrm{ml}$ of gelatin solution was added, and contents were mixed well and made into paste using a mortar and pestle. The implant preparation was followed as explained in the case of ESP-G.

\subsection{Characterization}

2.2a Compressive strength: Cylindrical specimens (diameter $1 \mathrm{~cm}$, height $0.8 \mathrm{~cm}$ ) were prepared and allowed to set at $30^{\circ} \mathrm{C}$ for $24 \mathrm{~h}$ and then cured at $80^{\circ} \mathrm{C}$. To measure the compressive strength, samples were loaded along the cylindrical axis in between the platens of the machine at a crosshead speed of $1 \mathrm{~mm} / \mathrm{min}$, using Instron 4501 model. The compre-
Table 1. Mechanical properties of ESP, BA and ESP-BA-G composite.

\begin{tabular}{lccc}
\hline S1. no. & Sample & $\begin{array}{c}\text { Compressive } \\
\text { strength (MPa) }\end{array}$ & $\begin{array}{c}\text { Tensile } \\
\text { strength (MPa) }\end{array}$ \\
\hline 1. & ESP-G & $8 \cdot 24$ & 37 \\
2. & BA-G & $3 \cdot 31$ & 30 \\
3. & BA+ESP(7:3 g) & $4 \cdot 1$ & 32 \\
4. & BA+ESP(5:5 g) & $4 \cdot 3$ & 34 \\
5. & BA+ESP(3:7 g) & $4 \cdot 7$ & 35 \\
\hline
\end{tabular}

The results given are an average of three specimens.

ssive strength was calculated from the break load and dimensions of the pellets. The results given are an average of three specimens (table 1).

2.2b Tensile strength: Cylindrical specimens (diameter, $0.5 \mathrm{~cm}$, height $0.8 \mathrm{~cm}$ ) were prepared and allowed to set at $37^{\circ} \mathrm{C}$ for $24 \mathrm{~h}$ and cured at $80^{\circ} \mathrm{C}$. Tensile strength of the sample was measured using Universal Testing Machine (INSTRON model 1405). The results given are an average of three specimens (table 1 ).

2.2c Infrared spectroscopy $(F T-I R):$ The IR spectra of the samples prepared were recorded in the $4000-400 \mathrm{~cm}^{-1}$ range using Nicolet Impact 400 Fourier Transform Infrared spectrophotometer with $\mathrm{KBr}$ pellet containing 2-6 $\mathrm{mg}$ of the sample.

2.2d X-ray diffractometry (XRD): The samples were analysed on a Siemens $500 \mathrm{X}$-ray powder diffractometer in a flat plane geometry using a source of $\mathrm{Cu} \mathrm{K} \alpha$ of wavelength, $1.5406 \AA$. The patterns were recorded in the region of 10 $90^{\circ}(2 \theta)$ in steps of $0.001^{\circ}$ with a counting time of $1 \mathrm{~s}$ in each step.

2.2e Thermogravimetric analysis: TGA of the samples prepared were carried out using a Seiko SSC $5200 \mathrm{H}$ in nitrogen atmosphere $(80 \mathrm{ml} / \mathrm{min})$ at a heating rate of $10^{\circ} \mathrm{C} / \mathrm{min}$. Primary weight loss of these materials as a function of temperature was recorded using this study.

2.2f Scanning electron microscopy (SEM): Dried samples were coated with gold ions using an ion coater (fisons sputter coater) under the following conditions: $0 \cdot 1$ Torr pressure, $200 \mathrm{~mA}$ current and $70 \mathrm{~s}$ coating time. Surface structure was visualized by scanning electron microscope (SEM model: LEICA stereoscan 440) using a $15 \mathrm{kV}$ accelerating voltage. 

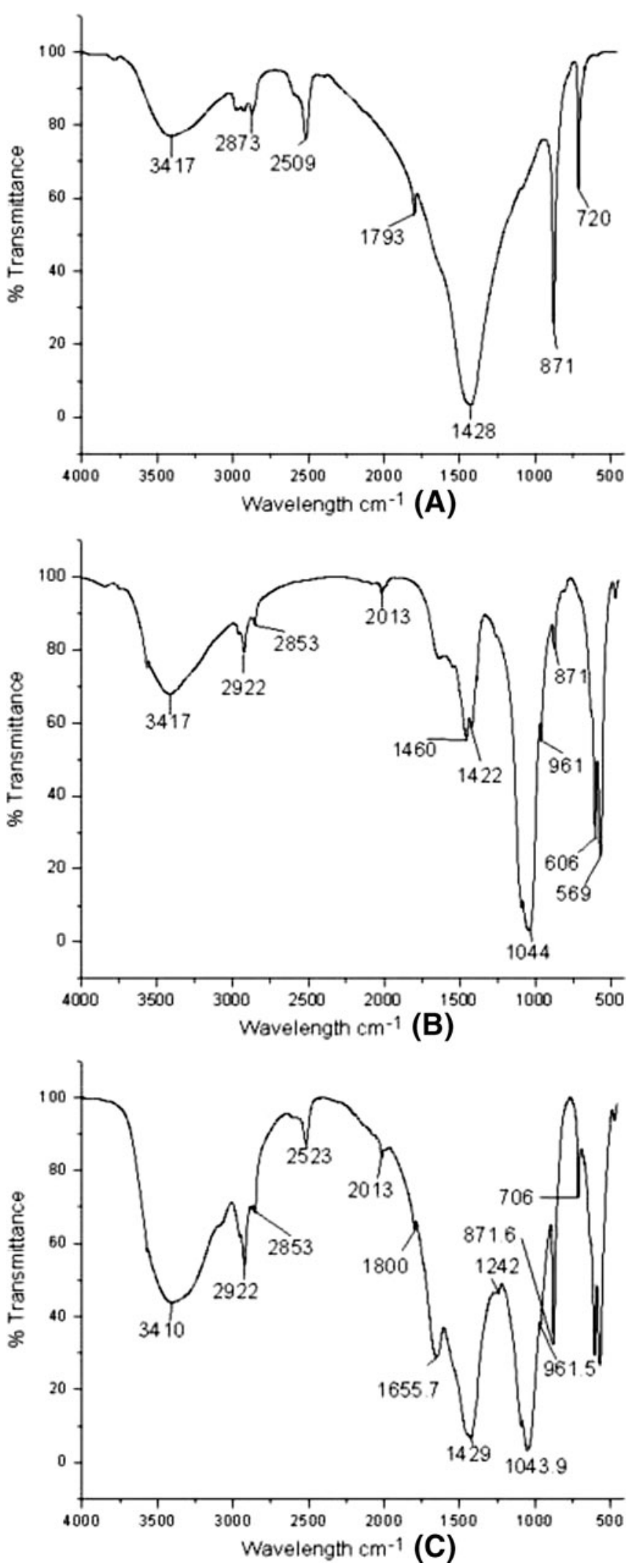

Figure 1. FTIR spectra of (A) ESP, (B) BA and (C) ESP+BA+G.

\section{Results and discussion}

\section{$3.1 \quad$ FTIR}

FTIR spectra of ESP, BA and BA-ESP-G are shown in figures $1 \mathrm{~A}, \mathrm{~B}$ and $\mathrm{C}$, respectively. The FTIR spectrum of ESP shows the absorption bands of carbonate at $871 \mathrm{~cm}^{-1}$ and a broad peak at around $1428 \mathrm{~cm}^{-1}$. This data confirms the presence of $\mathrm{CaCO}_{3}$ in the egg shell powder. In the case of BA (figure 1B), FTIR spectrum shows peaks at $961 \sim 1044 \mathrm{~cm}^{-1}$ and $569 \sim 606 \mathrm{~cm}^{-1}$ representing the characteristic well crystallized apatite phase. The peak at $961 \mathrm{~cm}^{-1}$ corresponds to $v_{1}$ stretching mode and $1044 \mathrm{~cm}^{-1}$ represents $\nu_{3}$ vibration mode of phosphate groups. The sharp peaks at $569 \sim 606 \mathrm{~cm}^{-1}$ are assigned to the bending mode of phosphate. The absorption bands at 1422-1460 and $876 \mathrm{~cm}^{-1}$ are due to the vibration mode of carbonate groups. IR spectrum of BA is similar to that of HA which was also confirmed in our earlier studies (Noorjahan and Sastry 2005). In the FTIR spectrum of BA-ESP-G (figure 1C), we can find the peak characteristic of both BA and ESP along with amide absorption bands at 1657 (amide I), and 1242 (amide III) representing gelatin.

\section{$3.2 X R D$}

Figures 2A-C represent the XRD patterns of ESP, BA and BA-ESP-G. A good agreement between the experimental data for BA and JCPDS standard for calcium hydroxyapatite (ref. code:89-6439) both in terms of intensity and despairing was obtained. The strong diffraction peaks corresponding to hydroxyapatite at $2 \theta$ position, 31.6 (211) plane together with other two peaks, 32.04 and 32.7, confirmed the structure of hydroxyapatite in crystal form (Ahmed and Ahsan 2008). In the case of ESP a strong peak at $29 \cdot 3$ for $\mathrm{CaCO}_{3}$ was observed. Other peaks are of less intensity and insignificant and this is in agreement with XRD of earlier studies (Park et al 2007). In the case of BA and ESP composite, the characteristic peaks of HA and ESP is seen. This data indicates that BA contains the crystallographic structure of hydroxyapatite and when it is mixed with gelatin and ESP the crystallinity of the composite is not lost.

\subsection{Mechanical strength}

Among the mechanical properties of bone repair materials, compressive strength is the most widely explored one. The strength of the composites depends on various factors like particle size of individual components, nature of adhesives and percentage of moisture present in the sample. The variation in the compression strengths of various compositions of BA-ESP-G are given in table 1. ESP-G alone has shown better compressive strength compared to other samples. The 

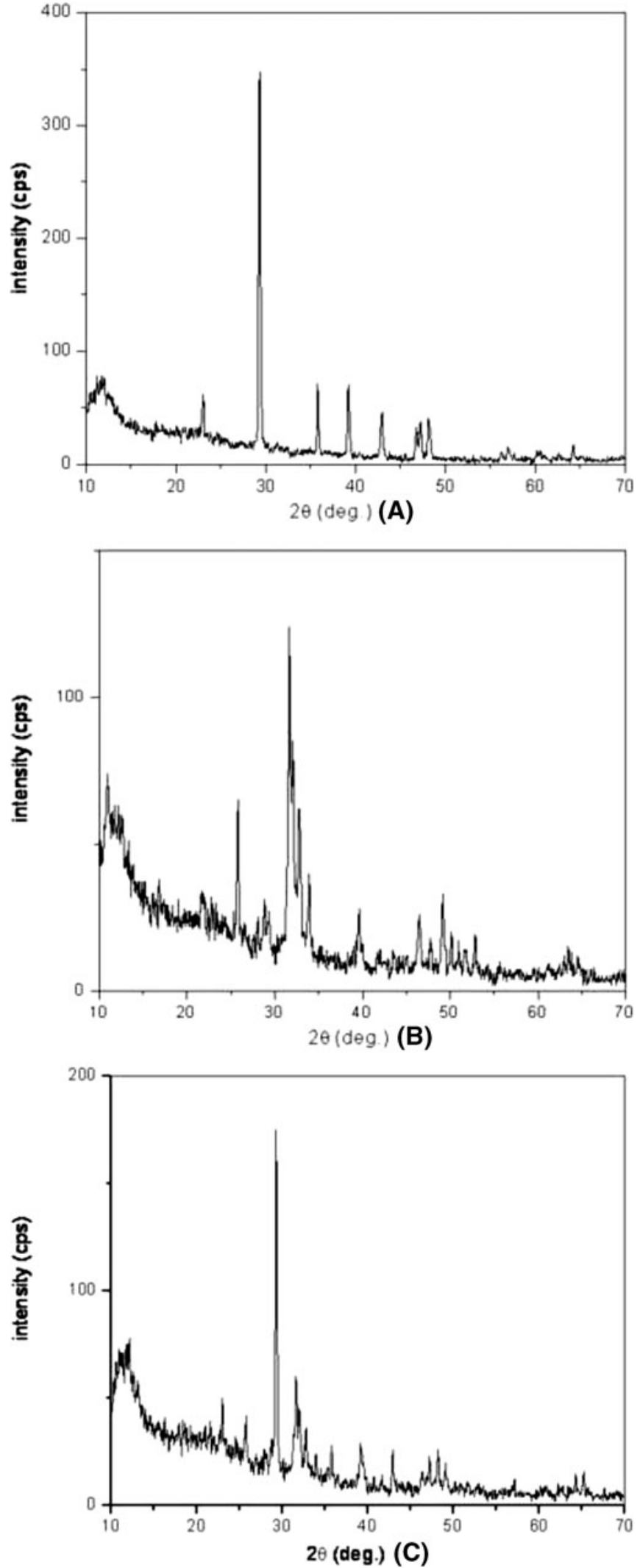

Figure 2. X-ray diffraction patterns of (A) ESP, (B) BA and (C) $\mathrm{ESP}+\mathrm{BA}+\mathrm{G}$. composite having stoichiometric ratio BA (3) and ESP (7) has shown better compressive strength (4.7 MPa) among the composites prepared. This compressive strength is less compared to those of synthetic HA implant (13-20 MPa) and natural bone (165 MPa). These implants cannot be used in defects of weight bearing bones, however, they may be used in the defects of non-weight bearing bones, e.g. maxillofacial bones, spinal cord bones etc.

\subsection{Tensile strength}

The tensile strength of ESP-G was found to be much higher than the BA-G (table 1). The composite having stoichiometric ratio of BA (3)-ESP (7)-G gave better tensile strength (35 $\mathrm{MPa}$ ) compared with other composites prepared.

\subsection{Thermogravimetric analysis}

The thermogram of ESP-BA-G composite is shown in figure 3. A three-step weight loss was observed. About $4 \%$ weight loss was observed up to $260^{\circ} \mathrm{C}$ due to loss of water or bound water. The second weight loss of $13 \%$ was observed between $260^{\circ} \mathrm{C}$ and $616^{\circ} \mathrm{C}$ which may be attributed to the decomposition of protein (gelatin, which is the binder) into $\mathrm{CO}_{2}$ and $\mathrm{H}_{2} \mathrm{O}$. The third weight loss of $20 \%$ which occurred between $616^{\circ} \mathrm{C}$ and $735^{\circ} \mathrm{C}$ may be attributed to the decomposition of $\mathrm{CaCO}_{3}$ component in ESP into $\mathrm{CaO}$ and $\mathrm{CO}_{2}$. About $63.5 \%$ of inorganic material is supposed to be hydroxyapatite, but $\mathrm{CaO}$ still remains above $735^{\circ} \mathrm{C}$.

\subsection{Scanning electron microscope}

The surface morphology of BA-ESP-G composite is shown in figure 4 . The porous nature of the composite is seen in lower magnification $(300 \times)$ as well as in higher magnification. SEM pictures indicate irregular pores ranging from 50 $150 \mu \mathrm{m}$ which is favourable for the bone ingrowth (Zang

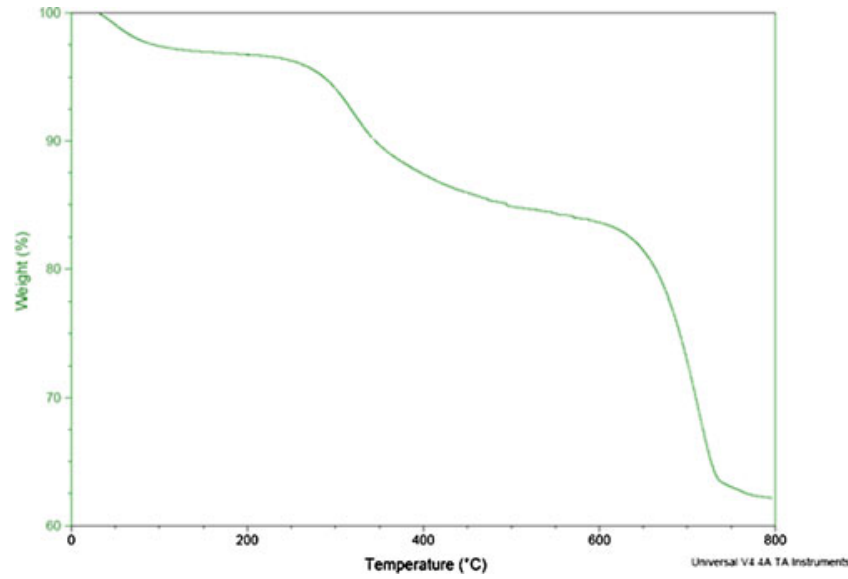

Figure 3. Thermogravimetric analysis graph of ESP+BA+G. 

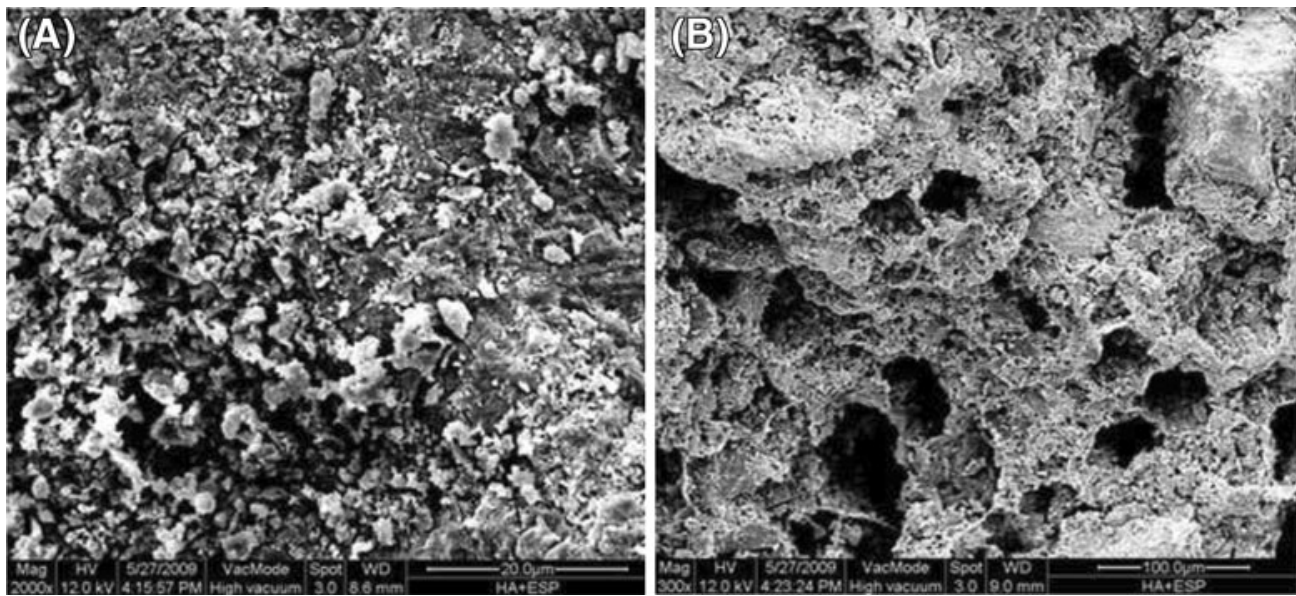

Figure 4. Typical SEM images of ESP+BA+G at (A) $2000 \times$ and (B) $300 \times$.

et al 2003). There is no distinct difference for the pore size distribution in the implant.

The FTIR spectrum of ESP has exhibited absorption peaks comparable to those of $\mathrm{CaCO}_{3}$, similar results were observed in the case of XRD studies also. Previous studies (Balliga et al 1998; Park et al 2007) have shown that the hen egg shell powder is a safe bone substitute which is easily available. FTIR spectrum and XRD of BA exhibited absorption peaks comparable to those of hydroxyapatite (Noorjahan and Sastry 2005). In earlier studies, calcined bone gave clinically good results when the same was used in rabbit mandible defects (Wafaa et al 1994). Based on these studies, we have prepared the ESP-BA-G composite. The compressive strength of the composite was found to be less, hence it may be used in defects of non-weight bearing bones such as maxillofacial and spinal cord bones. This will not only reduce the cost of bone graft but also egg shell waste can be utilized for this purpose.

\section{Conclusions}

The present study explored the possibility of using ESP along with BA as a bone graft material. Further studies may confirm the possibility of converting this solid waste of poultry industry into wealth.

\section{References}

Ahmed Samina and Ahsan Mainul 2008 Bangladesh J. Sci. Ind. Res. 43501

Balliga M, Davies P and Dupoirieux L 1998 Rev. Stomatol. chir Maxillofac. 9986

Best S M, Porter A E, Thian E S and Huang J 2008 J. Eur. Ceram. Soc. 281319
Dasgupta P, Singh A, Adak S and Purohit K M 2004 International symposium of research students on materials science and engineering, Chennai, 1

Dupoirieux L 1999 J. Oral Maxillofac. Surg. 37467

Dupoirieux L, Pourquier D and Souyris F 1995 J. Craniomaxillofac. Surg. 23187

Dupoirieux L, Neves M and Pourquier D 2000 J. Oral Maxillofac. Surg. 5840

Dupoirieux L, Pourquier D, Neves M and Teot L $2001 \mathrm{~J}$. Craniofac. Surg. 1253

Fowler B O 1974 Inorg. Chem. 13207

Gregory Lee Y, Ajay S, Darryl D'Lima D, Pamela Pulido A and Clifford Colwell W 2005 J. Arthroplasty 2057

Liji Sobhana S S, Sundaraseelan J, Sekar S, Sastry T P and Mandal A B 2009 J. Nanopart. Res. 11333

Monma H and Kamiya V 1987 J. Mater. Sci. 224247

Nakano T, Ikawa N I and Ozimek L 2003 Poult. Sci. 82510

Noorjahan S E and Sastry T P 2005 J. Biomed. Mater. Res. B75 343

Park Jin-Woo, Bae Sang-Ryul, Suh Jo-Young, Lee Dong-Hee, Kim Sang-Hyun, Kim Hyungiun and Lee Chong-Soo 2007 J. Biomed. Mater. Res. 87203

Prabakaran K, Balamurugan A and Rajeshwari S 2005 Bull. Mater. Sci. 28115

Rivera E M, Araiza M, Brostow W, Castano V M, Diaz-Estrada J R and Rogelio Rodriguez 1990 J. Mater. Lett. 41128

Sasikumar S and Vijayaraghavan R 2006 Trends Biomater. Artif. Organs 1970

Schaafsma A, Pakan I, Hofstede G J H, Muskiet F A J, Van Der Veer E and De Vries P J F 2000 Poultry Sci. 791833

Shiny V, Ramesh P, Sunny M C and Varma H K 2000 Mater. Lett. 46142

Sundaraseelan J and Sastry T P 2007 J. Biomed. Nanotech. 3401

Wafaa I A F, Osiris W G, Shamael S M and Khalil M R 1994 Biomaterials 20475

Yoshio M, Kazuo M and Sumio S 1990 J. Ceram. Soc. Jap. 981255

Zang S M, Cui F Z, Liao S S, Zhu Y and Han L 2003 J. Mater. Sci. 14641 